\title{
ALTERED BLOOD-NERVE BARRIER IN EXPERIMENTAL LEAD NEUROPATHY ASSESSED BY CHANGES IN ENDONEURIAL ALBUMIN CONCENTRATION ${ }^{1}$
}

\author{
JOSEPH F. PODUSLO, ${ }^{2}$ PHILLIP A. LOW, ANTHONY J. WINDEBANK, PETER J. DYCK, \\ CAROLE T. BERG, AND JAMES D. SCHMELZER
}

Peripheral Nerve Center, Mayo Clinic and Mayo Foundation, Rochester, Minnesota 55905

Received March 1, 1982; Revised May 24, 1982; Accepted May 24, 1982

\begin{abstract}
Assessment of the nerve microenvironment in experimental lead neuropathy permits an evaluation of the role that blood-nerve barrier disruption plays in the development of segmental demyelination observed during chronic lead intoxication. Endoneurial fractions from the sciatic nerves of 60 -dayold rats maintained on $4 \%$ lead carbonate for 3 to 24 weeks and their corresponding pair-fed controls were evaluated for protein and hydroxyproline distribution as well as for protein compositional changes determined by sodium dodecyl sulfate-pore gradient electrophoresis (SDS-PGE). A redistribution of both protcin and hydroxyproline was observed in the endoneurial fractions, and SDSPGE analysis revealed both qualitative and quantitative differences in a large number of proteins. In particular, the endoneurial albumin concentration began to increase after 6 weeks of the lead diet and reached a level at 24 weeks that was twice that of the pair-fed control. To demonstrate that this change in endoneurial albumin concentration resulted from a breakdown of the blood-nerve barrier and was not due to an accumulation of albumin, ${ }^{125} \mathrm{I}$-albumin was injected intravenously into rats maintained on a lead diet for different times. After waiting $48 \mathrm{hr}$ to allow equilibration of the labeled albumin in all body fluids, the specific activities for both serum and an endoneurial supernatant fraction containing the albumin were compared to pair-fed controls. The ratios of specific activity in lead-fed rats to controls showed a 1.3-fold increase at 6 weeks which increased by 3.9-fold at 12 weeks. These changes in the endoneurial albumin concentration, therefore, reflect an alteration in the blood-nerve barrier which commences 6 weeks after the lead treatment. Since lead reaches a maximum in the endoneurium at 5 weeks, these changes in the barrier probably are unrelated to the direct toxic effect of lead on Schwann cells and the subsequent onset of segmental demyelination. Furthermore, it is suggested that blood-nerve barrier breakdown in human peripheral neuropathies can be evaluated by determining a serum/endoneurial albumin concentration ratio using biopsied, neuropathic, human sural nerve.
\end{abstract}

Peripheral nerve fibers exist in a specialized compartment by virtue of a number of barriers, including the blood-nerve barrier and perineurial barrier (Bradbury, 1979), as well as cerebrospinal fluid-endoneurial fluid barrier (Low, 1983). Interstitial nerve edema (endoneurial edema) may ensue when the blood-nerve barrier is disrupted (Olsson, 1975). While an altered blood-brain

\footnotetext{
' This investigation was supported in part by the Peripheral Neuropathy Clinical Research Center Program Project (Grant NS14304) from the National Institute of Neurological and Communicative Disorders and Stroke of the National Institutes of Health, by the Amyotrophic Lateral Sclerosis Society of America, and by the Borchard Fund.

${ }^{2}$ To whom correspondence should be addressed at Membrane Biochemistry Laboratory, Peripheral Nerve Center, Neurology and Biochemistry, Mayo Foundation, Rochester, MN 55905.
}

barrier has been reported for neonatal lead intoxication (Pentschew and Garro, 1966), evidence for a similar breakdown in the adult blood-brain barrier has not been reported. Little information is available concerning the nature and mechanism of an altered blood-nerve barrier in lead neuropathy.

We assumed an alteration of the blood-nerve barrier in lead neuropathy since our finding of increased endoneurial area (Ohnishi et al., 1977) and increased endoneurial pressure (Low and Dyck, 1977) implied a net influx of fluid into the endoneurial compartment. Morphologic demonstrations of such an altered blood-nerve barrier using tracers have given somewhat variable results. Myers et al. (1980) reported a progressive disruption of the blood-nerve barrier which paralleled the rise in endoneurial fluid pressure. A massive breakdown of 
the blood-nerve barrier was not observed in another study although it was thought that horseradish peroxidase reaction product was increased slightly in endoneurial endothelial cells and macrophages of lead in comparison to control nerves (Dyck et al., 1980). Since these tracer techniques were nonquantitative and since normal mouse blood-nerve barrier is not fully impermeable to horseradish peroxidase (Arvidson, 1977), we chose to reexamine the blood-nerve barrier in experimental lead neuropathy using the alternative biochemical techniques of sequential measurements of natural and labeled albumin in the endoneurium and serum. These techniques detect alterations in protein composition of different endoneurial fractions which permit a fuller evaluation of the effect of lead on nerve. Sequential ${ }^{125} \mathrm{I}$-albumin studies also address the question of blood-nerve barrier breakdown versus albumin trapping or albumin utilization in endoneurium. Finally, the techniques that we have used are applicable to biopsied human nerves from patients with peripheral neuropathy for evaluation of barrier disruption.

\section{Materials and Methods}

Lead diet. Sixty-day-old male Spraguc-Dawley rats were placed in control and lead-treated groups. The rats maintained on the lead diet were allowed free access to standard rat food (Teklad, Madison, WI) which contained $4 \%$ basic lead carbonate, $\left(\mathrm{PbCO}_{3}\right)_{2} \mathrm{~Pb}(\mathrm{OH})_{2}$ (Fisher Scientific, Pittsburgh, PA). The control (pair-fed) group received a matched amount of the identical diet without the lead. Both the control and lead groups were maintained on their respective diets for up to 24 weeks. At various times after starting the lead diet, rats from each group were weighed and anesthetized with intraperitoneal sodium pentobarbital. Both sciatic nerves were exposed and excised for a length of 4 to $5 \mathrm{~cm}$ below the sciatic notch.

Endoneurial isolation, fractionation, and solubilization. The endoneurium was removed from the perineurium and epineurium by the microdissection techniques of Dyck et al. (1970). The endoneurium was fractionated according to the procedures described by Poduslo (1983). Briefly, the endoneurium was homogenized in deionized, distilled water with a ground glass homogenizer (100 or $250 \mu \mathrm{l})$. A uniform suspension was obtained which then was placed in the $30^{\circ} \mathrm{A}-100$ rotor for centrifugation in the Airfuge ultracentrifuge at $197,000 \times \mathrm{g}$ at $4^{\circ} \mathrm{C}$ so that $30 \mathrm{~S}$ particles are sedimented. An aqueous supernatant was obtained and was designated S-I. To the precipitate, $10 \%$ SDS was added followed by sonication for $1 \mathrm{hr}$ in a Branson B-220 ultrasonic cleaner. The sample then was spun in the Airfuge at $197,000 \times g$ to obtain a SDSsolubilized supernatant designated S-II. The remaining precipitate then was hydrolyzed in $1 \mathrm{~N} \mathrm{NaOH}$ from which aliquots were taken for protein and hydroxyproline determination.

Protein and hydroxyproline determination. Aliquots from both supernatant fractions and the hydrolyzed precipitate fraction were taken to determine the protein concentration according to the procedure of Lowry et al. (1951) as modified by Hess and Lewin (1965). Monomer standard bovine serum albumin (Miles Biochemical, Elk- hart, IN) was used for the protein determination in a range of 5 to $10 \mu \mathrm{g}$ using the least squares linear regression analysis. Aliquots also were taken to assay for hydroxyproline by the method of Stegeman and Stadler (1967) as modified by Micko and Schlaepfer (1979). This permits a quantitation of endoneurial collagen.

SDS-pore gradient electrophoresis (SDS-PGE). Proteins were separated by SDS-PGE on a linear gradient with a gel concentration of 10 to $20 \% \mathrm{~T}$ and $1 \% \mathrm{C}$ with the programmable LKB Ultragrad Gradient Maker according to the procedure described by Poduslo (1981b). A Tris/glycine buffer system was used. Proteins were solubilized at a concentration of approximately $1 \mu \mathrm{g}$ of protein $/ \mu \mathrm{l}$ of solubilizing solution containing $1 \%$ SDS, $(\mathrm{w} / \mathrm{v}), 0.0625 \mathrm{M}$ Tris (base), pH 6.8, 5\% $\beta$-mercaptoethanol (v/v), $0.002 \%$ bromophenol blue (w/v), and $10 \%$ glycerol $(v / v)$ (all final concentrations). Protein samples of approximately $30 \mu \mathrm{g}$ were subjected to electrophoresis for $3.75 \mathrm{hr}$ at constant power $(10 \mathrm{w})$ with the Buchler model 3-1500 constant power supply at a constant cooling temperature of $0^{\circ} \mathrm{C}$ maintained by the NESLAB RTE-8 refrigerated circulating bath. After electrophoresis, the slab gels were fixed in methanol/water/acetic acid (45/ $45 / 10, \mathrm{v} / \mathrm{v} / \mathrm{v}$ ) and stained for $2 \mathrm{hr}$ in $0.2 \%(\mathrm{w} / \mathrm{v})$ Coomassie blue in fixative. Gels then were destained and photographs were taken.

Data analysis. Positive images of the negatives for each photograph were taken, and these were scanned densitometrically using the Beckman DU8 microprocessor-controlled spectrophotometer. The dye-binding capacity for albumin was determined from the peak area obtained from these densitometric scans.

Radioiodination of albumin. Monomer standard bovine serum albumin (Miles Biochemicals) was solubilized in $0.1 \mathrm{M}$ sodium phosphate buffer, $\mathrm{pH} 7.4$, and iodinated by the chloramine $T$ procedure (Greenwood et al., 1963) using $2 \mathrm{mCi}$ of sodium ${ }^{125} \mathrm{I}$ (Amersham, Arlington Heights, IL), 13 to $17 \mathrm{mCi} / \mu \mathrm{g} \mathrm{I} \mathrm{I}^{-}, 0.7 \mathrm{mM}$ chloramine $\mathrm{T}$ (Eastman, Rochester, NY), and $1.2 \mathrm{~mm}$ sodium metabisulfite (Baker, Phillipsburg, NJ). Unreacted iodide was separated from the iodinated proteins by dialysis. A Beckman 8000 Gamma counter was used to determine radioactivity. A specific activity of $5.28 \times 10^{8} \mathrm{dpm} / \mathrm{mg}$ of albumin was obtained ( $75 \%$ counting efficiency). Chromatographic analysis of ${ }^{125} \mathrm{I}$-albumin on Gelman chromatography media (I.T.L.C. type SG; Gelman Instruments, Ann Arbor, MI) in $0.9 \% \mathrm{NaCl}$ revealed $96.6 \%$ of the radioactivity at the origin and $0.2 \%$ at the solvent front.

An aliquot of $120 \mu \mathrm{l}$ containing $28.5 \mu \mathrm{Ci}$ of ${ }^{125} \mathrm{I}$-albumin was injected into the left femoral vein of rats maintained on a lead diet for 6 weeks as well as the pair-fed control. Forty-eight hours later, blood samples were obtained and the right and left sciatic nerves were removed. This time period was chosen to allow for equilibration of ${ }^{125} \mathrm{I}$-albumin in the body fluids. Protein aliquots were taken from the serum, and the radioactivity was determined so that a specific activity for serum could be obtained. The endoneurium was fractionated according to procedures described previously and a specific activity was obtained for the aqueous supernatant fraction (S-I). Eighty to $92 \%$ of the total radioactivity of the endoneurium was found 
in the S-I fraction. This is consistent with the observation that albumin is the major component of endoneurial fluid (J. F. Poduslo and P. A. Low, manuscript in preparation) which, in turn, comprises a major part of the S-I fraction. A ratio of specific activities between the endoneurial S-I fraction and serum was obtained for the lead-treated animals which then was compared to a similar ratio for the pair-fed controls. Similar injections of labeled albumin were made at subsequent time points $(8,10,12$, and 16 weeks). Corrections for the decay of the radioactive ${ }^{125}$ I were made and normalized to the 6 -week time point.

\section{Results}

Effects of lead treatment on the protein and hydroxyproline distribution in endoneurial fractions. The aqueous supernatant fraction (S-I) of the endoneurium represents a fraction enriched in soluble proteins, including the proteins of the endoneurial fluid, soluble cytoplasmic proteins, and extrinsic membrane proteins that can be dissociated from membranes using this hypotonic homogenization procedure. 'The SDS-solubilized fraction (S-II) represents a preparation enriched in integral membrane proteins and glycoproteins. The fraction which is not solubilized (precipitate) represents predominantly connective tissue, in particular collagen, as is evidenced by the high hydroxyproline content (discussed later).

A redistribution of protein is observed in these endoneurial fractions as a consequence of the lead diet (Fig. 1). After 3 weeks of lead treatment, the protein values expressed as a percentage of the total lie within the normal range for untreated rats (Fig. 1, top). These percentages vary considerably as a function of nerve, distance from the nerve root, and species (Poduslo, 1983). For example, in the sciatic nerve of man, the S-I fraction represents 28 to $32 \%$ of the total, S-II is 42 to $43 \%$ of the total, and the precipitate is 25 to $30 \%$ of the total. In contrast, the human sural nerve S-I fraction represents 27 to $29 \%$ of the total, the S-II fraction is 25 to $27 \%$, and the precipitate is 44 to $47 \%$ of the total. This is a reflection of the number of myelinated fibers found in these nerve preparations as well as the amount of endoneurial connective tissue.

As the lead diet progresses, the protein found in the SI fraction increases and reaches a plateau with a corresponding decrease in the S-II fraction. In contrast, the precipitate fraction slowly increases after 6 weeks of the diet. These data suggest that, as segmental demyelination proceeds, the myelin protein contribution in the SII fraction decreases with a corresponding increase in soluble proteins, probably including degraded myelin proteins. The increase in protein in the precipitate could reflect an increase in connective tissue production.

Hydroxyproline also undergoes a similar redistribution in these endoneurial fractions as a consequence of the lead diet (Fig. 1, bottom). Again, the values at the 3-week point reflect the normal range of hydroxyproline in these fractions. This hydroxyproline content also varies as a function of nerve, distance from the nerve root, and species (Poduslo, 1983). For example, in the human sural and sciatic nerves, the amount of hydroxyproline fourd in a precipitate fraction varies between 94 annd $97 \%$ of total with 2 to $5 \%$ hydroxyproline found in the S-II fraction. This is indicative of the amount of myelinated fibers and the corresponding endoneurial space found in these nerve preparations.

After 24 weeks of the lead diet, the hydroxyproline content in the precipitate fraction increases to over twice the amount of hydroxyproline found at 6 weeks. A corresponding decrese in hydroxyproline is found in the S-II fraction. The level of hydroxyproline found in the S-I fraction is only slightly above background levels. These data suggest that, as a result of the lead diet, more connective tissue is produced after the 6-week time point.

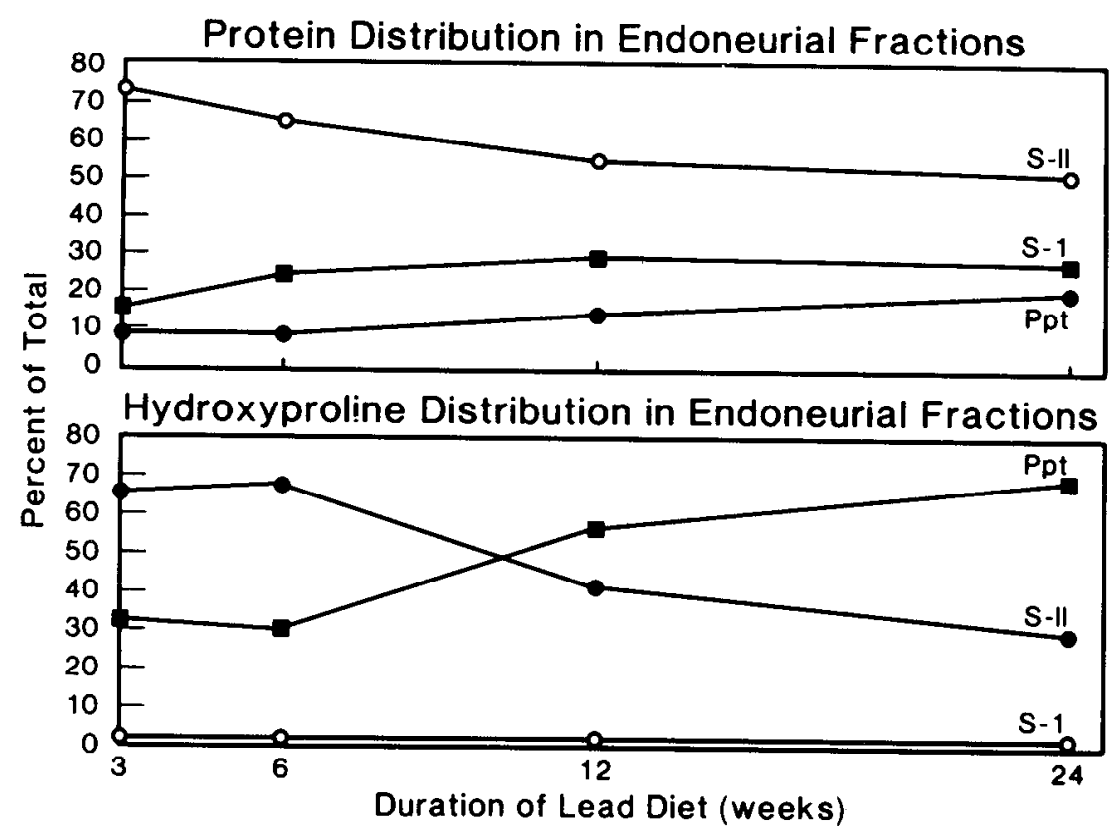

Figure 1. Protein and hydroxyproline distribution in endoneurial fractions following lead treatment. $S-I$, Aqueous supernatant fraction; $S-I I$, SDS-solubilized fraction; $P p t$, precipitate. 
The initial high levels of hydroxyproline found in the SII fraction might represent the hydroxyproline found in basement membrane collagen which is presumed to be a product of Schwann cells (Bunge et al., 1980; ArmatiGulson, 1980). Consequently, as Schwann cells become sick, their production of basement membrane decreases correspondingly or, conversely, the basement membrane can no longer be maintained by the Schwann cells.

SDS-PGE analysis of endoneurial fractions following lead treatment. A comparison of both endoneurial supernatant fractions from rats maintained on the lead diet for $3,6,12$, and 24 weeks with the corresponding pair-fed controls as evaluated by SDS-PGE is shown in Figures 2 and 3 . A number of qualitative and quantitative differences in the protein profile for the aqueous supernatant fraction (Fig. 2) are observed which become increasingly prominent as the lead diet progresses. The most striking change is the increase in albumin compared to the pairfed controls (discussed later). SDS-PGE analysis of the SDS-solubilized fraction is shown in Figure 3. A number of qualitative and quantitative changes also are observed, particularly at the later time points. This is characterized by a decrease in myelin proteins as the segmental demyelination becomes more extensive with the later time points. In particular, at 24 weeks, the $X$ and $P_{1}$ proteins are decreased dramatically compared to the pair-fed control, with a corresponding increase in a band between $P_{1}$ and $P_{r}$ and following the $P_{2}$ band (indicated by the arrows). In addition, changes in $P_{0}$ protein are observed at 24 weeks as evaluated by Coomassie blue stain. Changes in $P_{0}$ glycoprotein can be observed at 3 weeks (J. F. Poduslo, et al. unpublished observations) by an evaluation of radioiodinated lectin binding after electrophoresis (Poduslo, 1981a).

Further evaluation of the changes in the albumin concentration in the endoneurial aqueous supernatant fraction can be made by densitometric scanning of these Coomassie blue-stained gels. Figure 4 illustrates the densitometric scan of the endoneurial S-I fraction at 24 weeks following lead treatment (Fig. $4 C$ ) and the corresponding pair-fed control (Fig. $4 B$ ). Figure $4 A$ illustrates a number of qualitative and quantitative differences in the gel profile as indicated by the arrows and lines. These differences are evaluated further by the densitometric scan which emphasizes the major quantitative changes in the albumin concentration.

Quantitation of the dye-binding capacity obtained from similar densitometric scans of the S-I fraction after 6 and 12 weeks on the lead diet is shown in Table I. When the ratio of lead-to-control peak areas of albumin is normalized to the amount of protein applied to the gel, an increase in the albumin concentration is observed beginning at 6 weeks which reaches a level twice that of the pair-fed control by 24 weeks.

Intravenous injection of ${ }^{125}$ I-albumin. In order to demonstrate that the observed changes in the albumin concentration as evaluated by SDS-PGE result from an alteration of the blood-nerve barrier and a corresponding influx of serum proteins, ${ }^{125}$ I-albumin was injected intravenously into rats maintained on the lead diet for varying time periods as well as the corresponding pair-fed controls. Table II compares the radioiodinated albumin specific activities in serum and the endoneurial S-I fraction $48 \mathrm{hr}$ after intravenous injection. By normalizing the

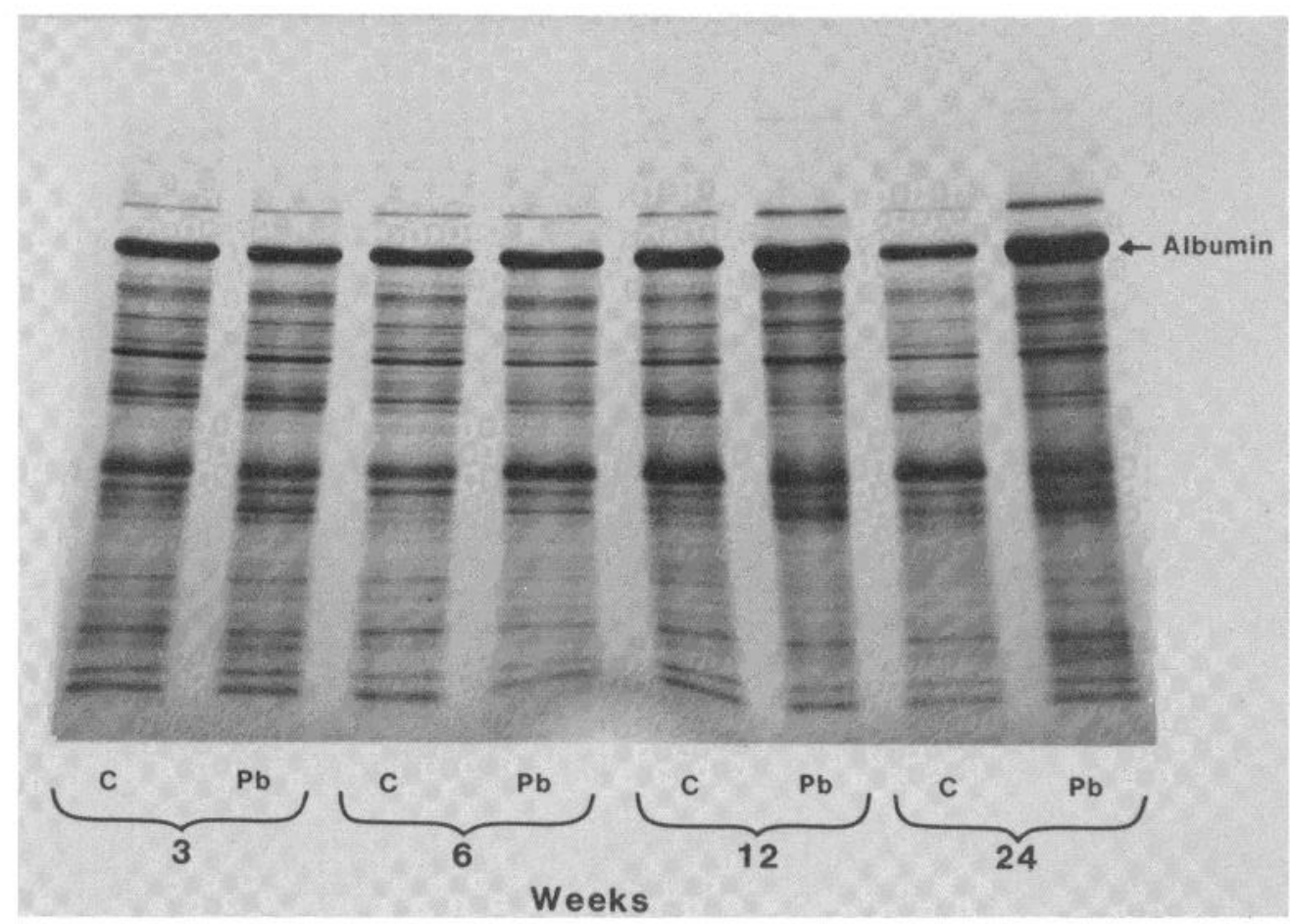

Figure 2. Sodium dodecyl sulfate-pore gradient electrophoresis (SDS-PGE) of the endoneurial S-I fraction at $3,6,12$, and 24 weeks following lead treatment. $C$, Pair-fed control; $\mathrm{Pb}$, lead diet. Linear gradient: 10 to $20 \% \mathrm{~T} ; 1 \% \mathrm{C} ; 10 \mathrm{~W}$ (constant); $3.75 \mathrm{hr} ; 0^{\circ} \mathrm{C}$; A Tris/glycine buffer system and Coomassie blue stain were used. The range of total endoneurial protein applied to the wells was 29.1 to $31.4 \mu \mathrm{g}$. 


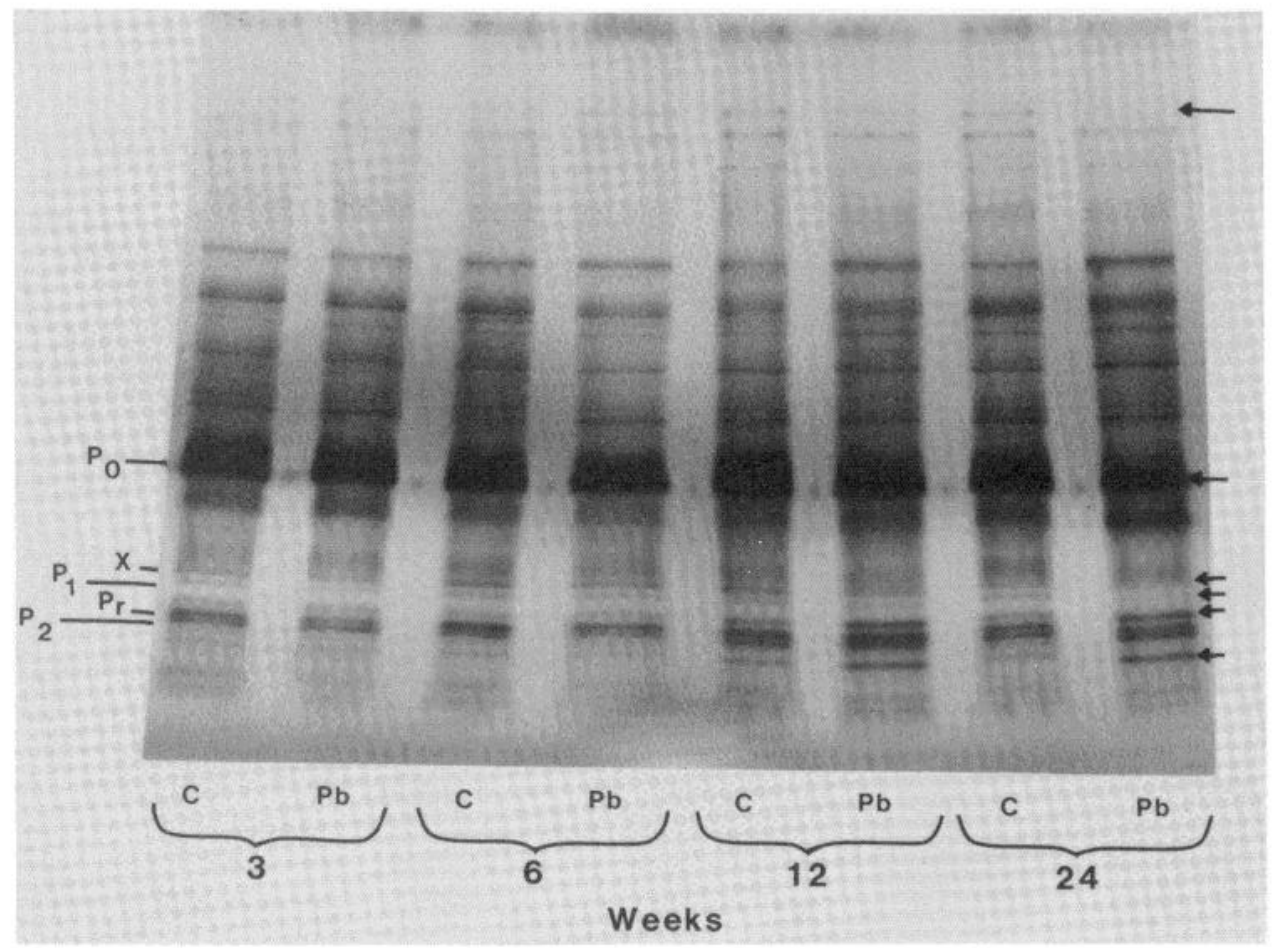

Figure 3. SDS-PGE of the endoneurial S-II fraction at 3, 6, 12, and 24 weeks following lead treatment. The same electrophoresis conditions as in Figure 2 were used. The range of total endoneurial protein applied to the wells was 29.5 to $31.2 \mu \mathrm{g}$. $P_{0}, X, P_{1}, P_{r}$, and $P_{2}$ are the major myelin proteins using nomenclature of Greenfield et al. (1980).

specific activity of the S-I endoneurial fraction with the serum specific activity and comparing this ratio to the similar ratio with the control animals, an increase in the ratio of lead to control is observed which ranges from 1.3 at 6 weeks to 3.9 at 12 weeks. The greater influx of labeled albumin into the endoneurium ir the lead-treated rats when compared to pair-fed controls suggests that an alteration of the blood-nerve barrier occurs after the 6 week time point. This alteration of the barrier continues to progress in a gradual fashion up to the 12-week point. A graphic comparison of the intravenous injection of radioiodinated albumin in the lead versus control groups with the endoneurial albumin concentration determined by densitometry after SDS-PGE is seen in Figure 5. Both experimental approaches, therefore, suggest a gradual alteration of the blood-nerve barrier which commences 6 weeks after lead treatment.

\section{Discussion}

The observed quantitative changes in the endoneurial albumin concentration between 6 and 24 weeks of the lead diet as determined by electrophoresis have a number of possible interpretations. These include (1) a gradual breakdown of the blood-nerve barrier which commences after 6 weeks and (2) an accumulation of albumin within the endoneurium due to $(i)$ entrapment within a new compartment, (ii) underutilization of albumin as a nutritional source by the endoneurium, or (iii) an alteration in the clearance of endoneurial fluid of which albumin is a major component.

The studies involving the intravenous injection of ${ }^{125} \mathrm{I}$ albumin provide evidence for a blood-nerve barrier breakdown in experimental lead neuropathy. Forty-eight hours after injection of the radioactive albumin, an increase in the labeled albumin was found in the endoneurium of lead-treated rats compared to controls which increased progressively as the lead diet continued. These changes were observed only after 6 weeks which is similar to the time frame for changes observed by electrophoresis. Simple albumin entrapment would be expected to follow a time course substantially slower which would correlate with the relatively slow accumulation of albumin as determined by electrophoresis. Since an increase in the radioactive albumin is observed at $48 \mathrm{hr}$ (Fig. 5), entrapment of albumin is not likely.

In addition to the numerous physiological roles assigned to albumin, such as being the principal agent responsible for maintaining the osmotic pressure of body fluids and its role in the transport of fatty acids, bilirubin, and other low molecular weight substances, albumin is also a source of amino acids to peripheral tissues (Peters, 1975). Consequently, underutilization of albumin by the endoneurium as a nutritional source should be considered as a reason for its accumulation in the endoneurium of rats maintained on the lead diet. Evaluation of the radioactivity in the S-II and precipitate fractions which might be expected to contain albumin that has been metabolized further did not indicate a decreased utilization compared to controls which could be correlated with the duration of the lead diet (data not shown). Consequently, it is unlikely that albumin accumulates in the endoneurium because it is not being utilized.

Little information is available concerning the mechanism of clearance of the endoneurial fluid. It is believed that the spinal fluid acts as a sink in the elimination of 


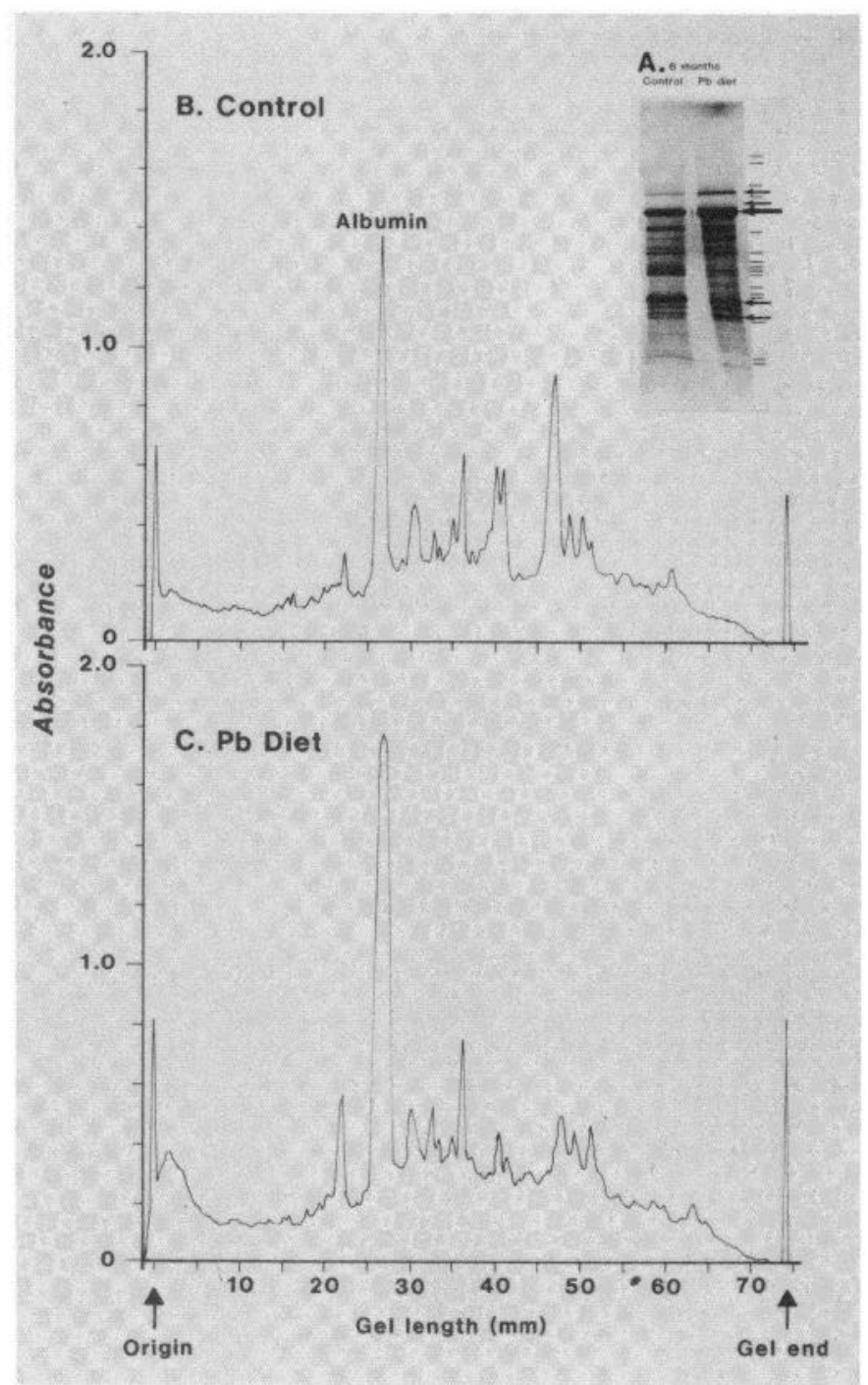

Figure 4. Densitometric scan of the endoneurial S-I fraction at 12 weeks following lead treatment. $A$, Coomassie blue-stained pore gradient gel of the endoneurial S-I fraction from pair-fed control and lead-treated rats. The arrows and lines indicate the qualitative and quantitative changes in a large number of proteins. $B$ and $C$, Densitometric scan of the lanes shown in A. $\lambda=500 \mathrm{~nm}$. The albumin peak is identified.

components of the endoneurial fluid (Bradbury, 1979). It is possible that, during the lead diet, the microcirculation of the endoneurial fluid is affected such that albumin is not cleared efficiently and, hence, accumulates in the endoneurium. Although the present experiments do not address this possibility, additional evidence has been presented which supports the breakdown of the bloodnerve barrier after 6 weeks of lead treatment. An increase in endoneurial fluid pressure has been observed in leadtreated rats which commences between 4 to 8 weeks and increases progressively (Low and Dyck, 1977). Windebank et al. (1980) also have observed an increase in endoneurial water content that begins to accumulate after 5 weeks and reaches a maximum by 7 weeks. Utilizing fluorescein isothiocyanate dextran compounds of graded molecular weight and horseradish peroxidase, Myers et al. (1980) correlated the progressive increase of endoneurial fluid pressure with the extravasation of these osmotically active macromolecules in lead neuropathy. In addition, Windebank and Dyck (1981), using quantitative track autoradiography, have demonstrated a 15fold increase in the rate of ${ }^{210} \mathrm{~Pb}$ accumulation in the endoneurium 70 days after the onset of chronic lead intoxication. The increased endoneurial pressure, nerve edema, extravasation of specific macromolecules, and ${ }^{210} \mathrm{~Pb}$ accumulation suggest a progressive alteration of the blood-nerve barrier which follows a similar time course of the albumin accumulation in the endoneurium. It is concluded, therefore, that the changes in the albumin concentration observed in the present experiments reflect an alteration of the blood-nerve barrier which commences 6 weeks after lead treatment.

Since lead reaches a maximal accumulation within the endoneurium within 20 and 35 days of lead feeding as determined by flameless atomic absorption spectrophotometry (Windebank et al., 1980) and segmental demyelination of teased fibers begins to appear at 35 days, the observed changes in the blood-nerve barrier probably are unrelated to the presumed direct toxic effects of lead on Schwann cells and the subsequent onset of segmental demyelination. The decrease in endoneurial lead, which, at 3 months, reached the level found in the perineurium (Windebank et al., 1980), can be correlated with the time course of barrier breakdown. This suggests that the breakdown of the blood-nerve barrier may play a role in depleting lead from the endoneurium.

It is well known that a steady state equilibrium exists between serum and specific fluid compartments for passively transferred proteins. The protein concentration of the fluid is dependent on the restrictive capacity of the barrier that separates these compartments. If barrier disturbances occur, then the transfer becomes facilitated, resulting in elevated protein levels in the fluid. By evaluating serum-cerebrospinal fluid concentration ratios for albumin, immunoglobulins, macroglobulins, etc., it has been possible to evaluate barrier integrity reliably in certain degenerative and metabolic diseases (Tourtellotte, 1970). Similarly, it should be possible to evaluate the blood-nerve barrier breakdown in human peripheral neuropathies having endoneurial edema and pathological

TABLE I

Changes in the endoneurial albumin concentration following lead treatment as determined by SDS.PGE

\begin{tabular}{|c|c|c|c|c|c|c|c|}
\hline \multirow{2}{*}{$\begin{array}{l}\text { Duration of } \\
\text { Lead Diet }\end{array}$} & \multicolumn{2}{|c|}{$\begin{array}{l}\text { Albumin Peak } \\
\text { Area }^{a}\end{array}$} & \multicolumn{2}{|c|}{$\begin{array}{l}\text { Protein Applied } \\
{\text { to } \mathrm{Gel}^{b}}^{b}\end{array}$} & \multicolumn{2}{|c|}{$\frac{\text { Peak Area }}{\text { Applied Protein }}$} & \multirow{2}{*}{$\frac{\text { Lead }}{\text { Control }}$} \\
\hline & Control & Lead & Control & Lead & Control & Lead & \\
\hline weeks & & & $\mu g$ & & & & \\
\hline 6 & 2.76 & 2.97 & 30.35 & 30.40 & 0.091 & 0.098 & 1.07 \\
\hline 12 & 2.71 & 4.35 & 29.14 & 31.36 & 0.093 & 0.139 & 1.49 \\
\hline 24 & 1.62 & 3.25 & 29.82 & 29.75 & 0.054 & 0.109 & 2.02 \\
\hline
\end{tabular}

${ }^{a}$ The peak area was assessed by a densitometric scan of a transparency (positive image). of a Coomassie blue-stained gel; adjacent lanes (endoneurial fraction S-I) on the same electrophoretic run were evaluated for dye-binding capacity.

${ }^{b}$ The total protein sample was applied to a $8 \times 25 \mathrm{~mm}$ well. The protein concentration was determined according to the procedure of Lowry et al. (1951) as modified by Hess and Lewin (1965). 
TABLE II

Comparison of ${ }^{125}$ I-albumin specific activities in serum and endoneurial fraction S-I $48 \mathrm{hr}$ after intravenous injection

\begin{tabular}{|c|c|c|c|c|c|c|c|c|c|}
\hline \multirow{2}{*}{$\begin{array}{l}\text { Duration of } \\
\text { Lead Diet }\end{array}$} & \multicolumn{3}{|c|}{ Control } & \multicolumn{3}{|c|}{ Lead } & \multirow{2}{*}{$\frac{\text { Lead }}{\text { Control }^{a}}$} & \multirow{2}{*}{$\left(\frac{\text { Lead }}{\text { Control }}\right)$} & \multirow{2}{*}{ Corrected $^{b}$} \\
\hline & S-I & Serum & S-I/Serum & S-I & Serum & S-I/Serum & & & \\
\hline weeks & \multicolumn{2}{|c|}{ cpm/ $\mu g$ protein } & & \multicolumn{2}{|c|}{$c p m / \mu g$ protein } & & & & \\
\hline 8 & 0.474 & 0.983 & 0.482 & 0.704 & 0.832 & 0.846 & 1.76 & & 2.06 \\
\hline 10 & 0.419 & 0.743 & 0.564 & 0.801 & 0.852 & 0.940 & 1.67 & & 2.30 \\
\hline 12 & 0.237 & 0.691 & 0.343 & 0.423 & 0.520 & 0.814 & 2.37 & & 3.85 \\
\hline
\end{tabular}

a $[\mathrm{cpm} / \mu \mathrm{g} \mathrm{S}-\mathrm{I}$ protein $/ \mathrm{cpm} / \mu \mathrm{g}$ serum protein] lead

[cpm/ $/ \mu \mathrm{g}$ S-I protein $/ \mathrm{cpm} / \mu \mathrm{g}$ serum protein] control

${ }^{b}$ Corrected for ${ }^{125}$ I decay relative to 6 -week time point.

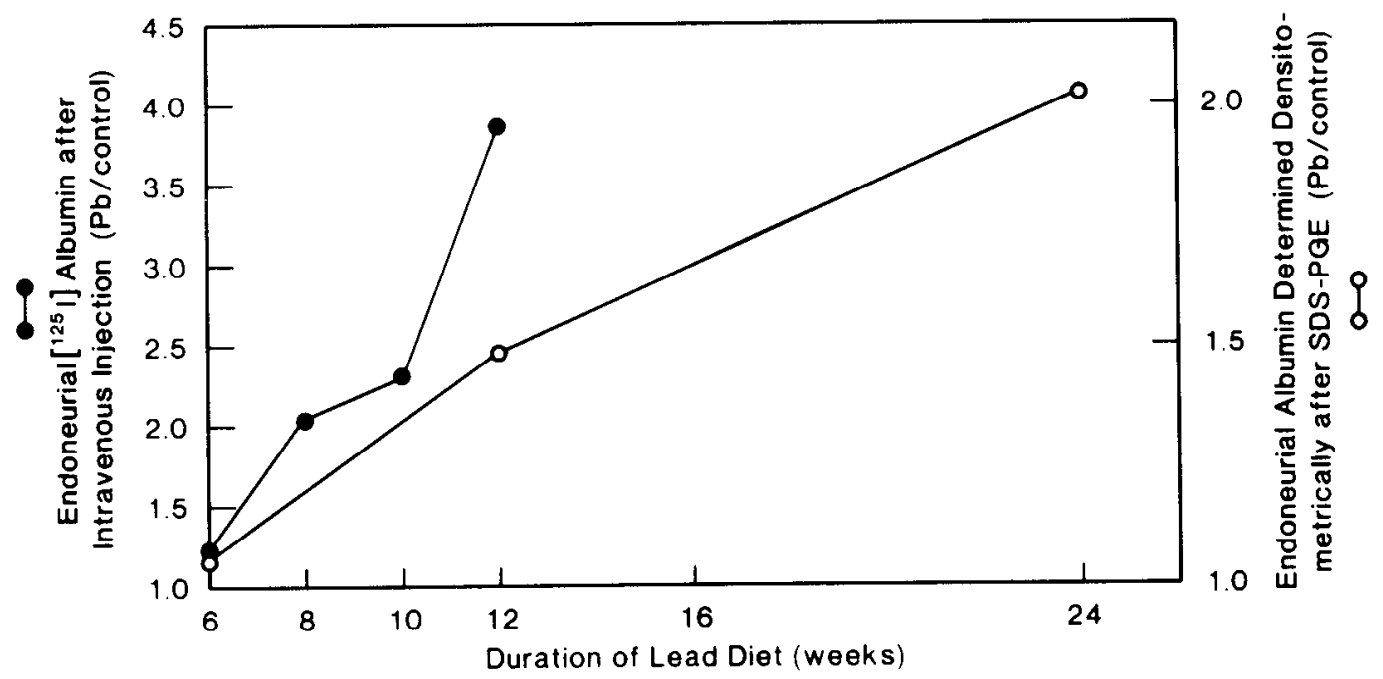

Figure 5. Time course of accumulation of albumin in the endoneurium: Comparison of ${ }^{125} \mathrm{I}-$ albumin after intravenous injection and albumin measured by densitometry after SDS-PGE.

changes suggestive of a barrier breakdown, such as the inflammatory neuropathies and certain toxic neuropathies. By evaluating a protein which is derived from serum and not produced locally within the endoneurium, such as albumin, it should be possible to evaluate barrier impairments from the fascicular biopsy of human sural nerve of patients with neuropathy (Poduslo et al., 1981). Since a lowering of the equilibrium concentration ratios can result from an altered barrier structure or an altered rate of fluid clearance, it becomes important to distinguish between these two possibilities.

\section{References}

Armati-Gulson, P. (1980) Schwann cells, basement lamina, and collagen in developing rat dorsal root ganglia in vitro. Dev. Biol. 77: 213-217.

Arvidson, B. (1977) Cellular uptake of exogenous horseradish peroxidase in mouse peripheral nerve. Acta Neuropathol. (Berl.) 37: 35-41.

Bradbury, M. (1979) The Concept of a Blood-Brain Barrier, John Wiley \& Sons, New York.

Bunge, M. B., A. K. Williams, P. M. Wood, J. Uitto, and J. J. Jeffrey (1980) Comparison of nerve cell and nerve cell plus Schwann cell cultures, with particular emphasis on basal lamina and collagen formation. J. Cell Biol. 84: 184-203.

Dyck, P. J., R. D. Ellefson, A. C. Lais, R. C. Smith, W. F. Taylor, and R. A. Van Dycke (1970) Histologic and lipid studies of sural nerves in inherited hypertrophic neuropathy:
Preliminary report of a lipid abnormality in nerve and liver in Dejerine-Sottas disease. Proc. Mayo Clin. 45: 286-327.

Dyck, P. J., A. J. Windebank, P. A. Low, and W. J. Baumann (1980) Blood-nerve barrier in rat and cellular mechanisms of leading-induced segmental demyelination. J. Neuropathol. Exp. Neurol. 39: 700-709.

Greenfield, S., S. W. Brostoff, and E. L. Hogan (1980) Characterization of the basic proteins from rodent peripheral nervous system myelin. J. Neurochem. 34: 453-455.

Greenwood, F. C., W. M. Hunter, and J. S. Glover (1963) The preparation of ${ }^{131}$ I-labelled human growth hormone of high specific radioactivity. Biochem. J. 89: 114-123.

Hess, H. H., and E. Lewin (1965) Microassay of biochemical structural components in nervous tissue. J. Neurochem. 12: 205-211.

Low, P. A. (1983) Endoneurial fluid pressure and microenvironment of nerve. In Peripheral Neuropathy, P. J. Dyck, P. K. Thomas, E. H. Lambert, and R. Bunge, eds., W. B. Saunders, Philadelphia, in press.

Low, P. A., and P. J. Dyck (1977) Increased endoneurial fluid pressure in experimental lead neuropathy. Nature 269: 427428.

Lowry, O. H., N. J. Rosebrough, A. L. Farr, and R. J. Randall (1951) Protein measurement with the Folin phenol reagent. J. Biol. Chem. 193: 265-275.

Micko, S., and W. W. Schlaepfer (1979) Proximo-distal gradient of endoneurial collagen in rat peripheral nerves. J. Neurochem. 32: 221-223.

Myers, R. R., H. C. Powell, H. M. Shapiro, M. L. Costello, and 
P. W. Lampert (1980) Changes in endoneurial fluid pressure, permeability and peripheral nerve ultrastructure in experimental lead neuropathy. Ann. Neurol. 8: 392-401.

Ohnishi, A., K. Schilling, W. S. Brimijoin, E. H. Lambert, V. F. Fairbanks, and P. J. Dyck (1977) Lead neuropathy. 1. Morphometry, nerve conduction, and choline acetyltransferase transport; new findings of endoneurial edema associated with segmental demyelination. J. Neuropathol. Exp. Neurol. 36: 499-518.

Olsson, Y. (1975) Vascular permeability in the peripheral nervous system. In Peripheral Neuropathy, P. J. Dyck, P. K. Thomas, and E. H. Lambert, eds., Vol. 1, Section 2, pp. $190-$ 200, W. B. Saunders Co., Philadelphia.

Pentschew, A., and F. Garro (1966) Lead encephalo-myelopathy of the suckling rat and its implications on the porphyrinopathic nervous diseases. Acta Neuropathol. (Berl.) 6: 266278.

Peters, T. (1975) Serum Albumin. In: The Plasma Proteins, F. W. Putnam, eds., pp. 133-181, Academic Press, New York.

Poduslo, J. F. (1981a) Developmental regulation of the carbohydrate composition of glycoproteins associated with central nervous system myelin. J. Neurochem. 36: 1924-1931.

Poduslo, J. F. (1981b) Glycoprotein molecular weight estima- tion using SDS-pore gradient electrophoresis: Comparison of Tris-glycine and Tris-borate-EDTA buffer systems. Anal. Biochem. 114: 131-139.

Poduslo, J. F. (1983) Glycoproteins of the peripheral nervous system. In Peripheral Neuropathy, P. J. Dyck, P. K. Thomas, E. H. Lambert, and R. Bunge, eds., W. B. Saunders, Philadelphia, in press.

Poduslo, J. F., C. T. Berg, J. L. Karnes, and P. J. Dyck'(1981) Human sural nerve biopsy: Endoneurial protein and glycoprotein microanalyses. Trans. Am. Soc. Neurochem. 12: 141.

Stegeman, H., and K. Stalder (1967) Determination of hydroxyproline. Clin. Chim. Acta 18: 267-273.

Tourtellotte, W. W. (1970) On cerebrospinal fluid IgG quotients in multiple sclerosis and other diseases. A review and a new formula to estimate the amount of IgG synthesized per day by the central nervous system. J. Neurol. Sci. 10: 279-304.

Windebank, A. J., and P. J. Dyck (1981) Kinetics of ${ }^{210} \mathrm{~Pb}$ entry into the endoneurium. Brain Res. 225: 67-73.

Windebank, A. J., J. T. McCall, H. G. Hunder, and P. J. Dyck (1980) The endoneurial content of lead related to the onset and severity of segmental demyelination. J. Neuropathol. Exp. Neurol. 39: 692-699. 